\title{
Being and Becoming Maya in Chan Kom: Towards Heideggerian Interpretations of Cultural Transformation
}

\author{
Andrew R. Hatala \\ Department of Psychology, University of Saskatchewan, Saskatoon, Canada \\ Email: Andrew.hatala@usask.ca
}

Received November $27^{\text {th }}$, 2012; revised December $29^{\text {th }}, 2012$; accepted January $14^{\text {th }}, 2013$

\begin{abstract}
Between the years of 1931 and 1950, Robert Redfield, social science researcher and ethnographer from the University of Chicago, and Alfonso Villa Rojas described subtle and explicit cultural changes within Chan Kom, a Maya village in North-Central Yucatán. Using the theoretical framework developed by Martin Heidegger regarding worlds, being and style, this paper explores the social and cultural changes in the Maya village of Chan Kom in order to deepen our understanding of how cultural change occurs more generally. Through this analysis, several aspects of cultural change emerge.
\end{abstract}

Keywords: Maya; Cultural Change; Heidegger; Being; Styles; Worlds

\section{Introduction}

Maya peoples in and around the Yucatán peninsula of Central and North America share an interesting and rich history. Archeological and ethnographic records suggest that Maya cultural groups occupied the Yucatán peninsula as far back as 200 B.C., flourished around 700 A.D. with the founding of Chichen Itza and other great Maya cities, and continued to subsist during the Spanish occupation in the $16^{\text {th }}$ century up to and including the modern era of the $21^{\text {st }}$ century (Coe, 1999; Thompson, 1970; Waldram, Cal, \& Maquin, 2009). When speaking of "Maya" peoples it is important to acknowledge that although the term Maya often invokes a notion of singularity, something akin to the term "Aboriginal" in Canada or "Indigenous" more generally, in reality, however, there are 31 distinct Maya cultural groups with mutually unintelligible languages inhabiting the areas of what have become today the nations of Mexico, Guatemala, El Salvador, Honduras and Belize. Throughout their extensive history, Maya cultural groups and their practices - use of equipment, languages, religious ceremonies, rituals, modes of subsistence, and ways of beingunderwent both subtle and explicit transformations (Kahn, 2006; Little, 2004; Maurer, 1997; Watanabe, 1992). Several contemporary researchers from North and Central America have attempted to portray and interpret these processes of cultural change. Between the years of 1931 and 1948, in particular, Robert Redfield, social science researcher and ethnographer from the University of Chicago, described profound cultural changes within Chan Kom, a Yucatec Maya village in NorthCentral Yucatán. ${ }^{1}$ Beginning in 1931, Redfield, along with a Yucatán local named Alfonso Villa Rojas, studied the cultural practices of the Chan Kom peoples. Together, Rojas and Redfield produced an ethnographic account entitled "Chan Kom: A

\footnotetext{
${ }^{1}$ The Yucatec Maya are the largest group of Maya in Central and North America living primarily in Mexico’s Yucatán state. They commonly identify themselves simply as "Maya” with no further ethnic subdivision (unlike in the Highlands of Western Guatemala). Throughout this paper, therefore, we draw on the terms "Maya" and "Yucatec" interchangeably in reference to the peoples living in Chan Kom.
}

Maya Village”. Some years later in 1948, Redfield returned to the same village to explore the extent to which these Maya peoples and their cultural practices underwent changes since his last report. These findings produced a second book entitled, "A Village that Chose Progress".

The following paper examines and compares the two ethnographic accounts of Chan Kom by Redfield and Rojas (1934) and Redfield (1950) in order to develop an understanding of Maya cultural change in Chan Kom. Heideggerian perspectives on worlds, being and style form the analytic lens through which cultural transformations within and amidst the peoples of Chan Kom are interpreted. This paper begins by describing this Heideggerian lens. Then, in the main sections of the paper, three catalysts for cultural change are presented followed by two examples of cultural change. Overall, it is suggested that cultural change is a complex process that involves a blending and mixing of many worlds, styles and ways of being, and is therefore not a simple linear replacement of one way of life over another. It is argued that when speaking of local Maya communities it is essential to adopt a critical stance toward unbridled claims of static "traditional" knowledge or ways of life that are insulated or hermetically sealed from externally-generated influences. As we see in this analysis, cultural knowledge and practices are modified by social and political change and are heteroglossic, fluid and permeable across time and space (Good, 1994; Hatala, 2010; Keesing, 1990; Little, 2004; Molesky-Poz, 2006; Watanabe \& Fischer, 2004). This paper concludes by presenting key points regarding Heideggerian interpretations of cultural transformation and societal change.

\section{Heidegger on Worlds, Being, and Style}

Heidegger’s (1962) “Being and Time” and his (1971) “The origin of the Work of Art" outline the ontological structures and intimate relations between worlds, being, and style. For Heidegger, there are four senses of the term worlds: 1) the universe and all therein (categorical substances); 2) the way of being these substances or the realm of objects; 3) social worlds such as the academic world or the theater world; and 4) finally 
"world" can designate the ontologicico-existential concept of worldhood; that is it embraces the a prior character of worldhood in general (Heidegger, 1962: p. 93). This is the structure of the background, or any world that on the basis of which we understand ourselves. For the purposes here, the term "world" refers to the third category of primarily social worlds wherein humans reside. In this way, world is the whole context of shared equipment, roles, and practices on the basis of which one can encounter entities and other people as intelligible. Using Heidegger's classic example, one encounters a hammer as a hammer in the context of other equipment such as nails and wood, and in terms of social roles such as being a carpenter or a handyman etc. This relational totality between the entirety of equipment and the appropriate social roles forms the basic ontological structure of the worlds in which humans exists. The term "culture" then signifies the emergent properties among different worlds in their relations to one another. In this way, culture is, on the one hand, a broader notion that runs through, connects and informs individual worlds, while on the other hand, it is closer to the individual and more fundamental due to its reflection across and within many particular worlds. ${ }^{2}$

The particular term for being used by Heidegger to reference the way in which humans' be-in-the-world is dasein. ${ }^{3}$ For Heidegger, the unique human way of being lies in our ability to take a stand on our being - thereby making our being an issue for us. The way in which dasein takes a stand on its being is by way of the equipment found within worlds that are intelligible. Therefore, Heidegger suggests that our way of being is a kind of activity through which we give ourselves an identity ${ }^{4}$ by taking up a series of practices. In this way, Heidegger argues that existence itself is our essence or, in other words, dasein is a kind of being that through its activity it gives itself a nature or essence. This activity of being, according to Heideggar, is intimately connected with the worlds around us because the ways in which we derive our nature or take a stand on our being are possible only insofar as equipment functioning within a referential totality of a world is available to us within a particular culture. For example, an individual can only take up being a teacher if the teaching world exists for them. Hence, possibilities of being are limited to the available worlds within a culture. This further implies that humans and the world cannot be meaningfully separated. Humans always exist within or are absorbed by the "world", thus Heidegger firmly argues against Cartesian subject/object distinctions. The world, Heidegger asserts, is a determination of dasein's being-to be a self the structure of a world must exist.

According to Heidegger, Style is the way in which beings are revealed - what he calls the truth of their being - which determines worthwhile or relevant actions within and across worlds and cultures. There are therefore two meanings of style. The

\footnotetext{
${ }^{2}$ Heidegger does not specifically define culture in this way and most of his references to culture are static and essentialist. That being said, in order to proceed with the following objectives a basic operational understanding of culture should be posited. As such, culture primarily refers to the broader or overarching system of meanings that reflect within individual worlds, which is somewhat reflective of Heidegger's fourth understanding of worldhood as the "worldhood may have its modes in whatever structural wholes any special 'worlds' may have at the time” (Heideggar, 1962: p. 93).

${ }^{3}$ Dasein literally translates to English as there-being to signify that humans are always and only intelligible within a world and cannot be understood apart from worlds.

${ }^{4}$ Identity for Heidegger is the fusion of horizons between the worlds and the unique stand one takes one their being with regards to the equipment and roles found therein.
}

first is a style of worlds. This style is portrayed as the ways in which a carpenter, for example, reveals specific actions that determine the truth of his being. This style serves as the basis upon which old practices are conserved and new practices are developed. The second is a style of culture. This style is portrayed as the ways in which shared understandings of masculine or feminine, for example, are determined or interpreted for particular peoples. These cultural styles determine not only the general category of male or female but also impact the ways in which specific worlds such as a carpenter's are lived.

At the broadest level, then, style opens a disclosive space in three ways: 1) by coordinating everyday practices and actions; 2) by determining how things and people matter; and 3) by being what is transferred from situation to situation. According to Heidegger, these three functions of style determine the way anything shows up and makes sense within a particular culture (Heidegger, 1971). Style, Heidegger says, prescribes various practices as dominant and subordinates others or ignores others altogether. The cultural style, Heidegger continues, primarily manifests in artifacts and bodily skills or habits. Therefore, it is misleading to think of a cultural style as something inner such as a belief system, scheme, or framework; rather, style for Heidegger, is a disposition to act in certain ways in certain situations. In this way, style is invisible and withdrawn from our awareness both because it is in our comportment, and also because it is manifest in everything we see and do and is thus too pervasive to notice. Our style is thus the nearest-and-the-farthest thing away from us, as Heidegger puts it; that is, our particular way of being or the cultural styles in which we use to take a stand on our being are so obvious, so close to us, that they become the hardest thing to see and the farthest things from us.

\section{Being and Becoming Maya in Chan Kom}

After describing Heidegger's (1962, 1971) approach to worlds, being and style, the next objective is to apply these concepts to cultural transformation in Chan Kom as outlined by Redfield and Rojas (1934) and Redfield (1950). This section is analyzed in two parts. First, three catalysts for change are presented thereby exploring possible "How's" of cultural change, these include: 1) the desire to be a pueblo and a "free municipality”; 2) contact with Americans and Chichen Itza; and 3) the introduction of the Spanish language within the Chan Kom school in general or through the local teacher in particular. Second, two consequences of change are outlined thereby exploring in more detail possible "What's" of cultural change, including: 1) equipment and modes of dress; and 2) understandings towards and practices of religion.

\section{Catalysts for Cultural Change}

The three catalysts for change discussed, in a way open new worlds and thus new styles of being for the residents of Chan Kom, although this occurs in somewhat different ways. Around the 1920s the residents of Chan Kom severed ties with neighboring villages, allowing them to become an independent village (pueblo)—a goal shared among the majority of Chan Kom residents. According to Redfield and Rojas (1934), becoming a pueblo has two implications: 1 ) the village begins to take on the appearance of a Spanish American town; and 2) the village begins to secure legal confirmation of the communal 
lands. In the summer of 1928 Chan Kom officially obtained pueblo status, however, its desire for progress did not end there. In the 1930s Chan Kom's residents worked to secure its status as a "free municipality", which differs from a pueblo in that it is more "free" having its own president, judge and justice system, in addition to its own officers chosen by the community. This new status of municipio was officially granted in 1935 with a total population of about 450 .

The goal and motivation for these political and social changes was, according to Redfield (1950), primarily ideals of liberty and freedom.

$[W]$ hile freedom is a conscious ideal of these people and a goal toward which they have striven... it is not a freedom of the spirit, not a liberation from taboo and ancient moral imperative, ...but freedom economic and political (p. 161).

Since Spanish occupation of the Yucatán peninsula and Central America, native Yucatec residents of the area have been subjected to subtle and explicit forms of persecution (Coe, 1999; Thompson, 1970). More recently, in 1847, a War of the Castes broke out on the peninsula creating dissention and strife between different local communities. The background desire and motivation to become an independent village was thus freedom from centuries of serfdom and political conflict. The people of Chan Kom were driven to emancipate themselves from previous oppressions, and their success in gaining a "free municipal" is primarily interpreted and internalized as a glorious and triumphant revolution (Redfield, 1950).

One way cultural transformation occurred in Chan Kom, it could be argued, was by subtle changes in Maya ways of being as result of contact with new social worlds. To be a free municipio, a broadening of the political and social milieu was necessary. As a result of this broadening of horizons, new worlds, styles and social roles were thus created or opened to the Chan Kom residents, such as judge, law giver, political leaders, and town council members. These new worlds and styles allowed the peoples of Chan Kom to take stances on their being that were previously unavailable to them, thereby facilitating processes of cultural change. From a Heideggarian perspective, then, one way in which cultural change occurred in Chan Kom, or can occur in general, is due to the introduction of new worlds, and styles of being.

Contact with American styles and worlds as well as increased contact with Chichen Itza, also served as a catalyst for cultural change in Chan Kom. As much as the Chan Kom villagers desired political progress, they also, with new interest and excitement, turned their attention towards Chichen Itza-the great symbol of their cultural roots. Redfield and Rojas (1934) note that the Chan Kom people envisioned the city of Chichen Itza not solely as a symbol of a forgotten past, but also a guide to the future. In this way, during the 1920s, the Chan Kom peoples organized the building of a new road- "road to the light”- that would strengthen their connection with Chichen. As they constructed their road, contact began with American sociologists, anthropologists and archaeologists that were working on the restoration of Chichen. Redfield (1950) notes that, in part, the villagers interpreted the American workings as the "Red People" who were mentioned in ancient stories to return one day to initiate progress and peace for the Maya peoples. Chan Kom residents quickly recognized the knowledge and skills of the Americans, with their motor vehicles and their abilities to make the stones of the ancient pyramids go back into their places (Redfield, 1950). The powers of the American peoples, Redfield (1950) notes, came to be incorporated into Chan Kom's dreams for progress.

From a Heideggerian perspective, contact with the Americans and the rebuilding of Chichen Itza opened new worlds and styles in two related ways. Firstly, the American equipment, social roles, and sporting games such as baseball, spilled into the Chan Kom ways of life. These unique skills were desired and accepted by the Chan Kom peoples based on their interpretation of the Americans as the return of the "Red People” (Redfield, 1950). This aspect is similar to the broadening of horizons mentioned previously.

In a second way, contact with Americans not only threw open new worlds that were directed toward the future, but also facilitated a surging of the past. For example, Redfield (1950) notes that things once on the periphery, such as traditional stories of Chichen and the King of the Itza's, were now uncovered and brought again into the daily discourse of the Chan Kom peoples. From here, Heidgger (1971) suggests that great works of art, as he calls them, such as the pyramids of Chichen for the Maya's and the Greek temples for the ancient Greeks, disclose worlds for those people by articulating their style. By rebuilding the temples and the great cities at Chichen, then, Americans facilitated this opening process for the villagers of Chan Kom. Moreover, Heidegger argues that great works of art-or things that disclose a world and articulate a style-function to allow people to witness and understand the style of their culture by displaying a glamorized exemplar. Thus, Heidegger suggests that works of art, such as the great city of Chichen, do not merely articulate a style, they illuminate it. From this perspective, the rebuilding of the Chichen and the building of "the road of light” connecting Chan Kom to this ancient place, illuminated and brought to the surface ways of being long since on the periphery of life, which together with the new worlds already opened through contact with the Americans, served as significant catalysts for cultural change. ${ }^{5}$

A final catalyst for cultural change to be explored involves the dealings with the Chan Kom School in general or the teacher in particular. From this perspective the introduction and education of the Spanish language is most relevant. Although the Spanish language had been slowly spreading since the Spanish occupation of Yucatán in 1527, its adoption and use was largely reserved to those of somewhat privileged class and residents of larger urban centers (Thompson, 1970). Villages on the outskirts of the Peninsula isolated by the thick bush of the forest and with minimal access to formal education, took up Spanish only to a limited degree. This began to change for Chan Kom residents, however, as their march for progress in the early 1920s began. The first school in Chan Kom was built in 1917 with mild success and the cycling of 7 different teachers over a period of 4 years. Only after receiving pueblo status during the 1920s and 1930s did the Chan Kom School become a catalyst for cultural change. Indeed, villagers who speak Spanish before 1930 was under 14 percent; whereas, in the late 1930s and 1940s, after the school had been established for some time with a stable teacher, there was over 50 percent Spanish speaking residents in Chan Kom. This development is significant in Chan Kom only insofar as Spanish, according to Redfield (1950), was interpreted as the language of progress.

\footnotetext{
${ }^{5}$ The relation between reclaiming old ways of being and the desire for progress and adoption of new modes of being is a central theme running throughout Redfield's work. It will be discussed in more detail in latter sections.
} 
All literature from the "out side" world was in Spanish: newspapers, magazines, maps, monetary systems etc. The school and teachers of Chan Kom are then witnessed and understood as the principle cause of these linguistic changes.

For Heidegger, what ultimately bestows the material for a new cultural style is the style of a people's language. The working of art, as Heidegger (1971) puts it, or the ways in which a peoples' being is reflected and illuminated to them, takes place in a clearing "which has already happened unnoticed in language” (p. 74). For Heidegger, language is central to being in that it brings beings as beings into the open for the first time and further makes possible the founding of truth. The introduction of the Spanish language, then, is important for the current analysis insofar as it founds new truths of being or the ways in which beings are revealed. These new styles founded within the adoption of or introduction to a new language are, however, at first barely intelligible. Therefore, Heidegger notes that this founding of new worlds and styles is only possible insofar as it can be grounded to or somehow connected with previous modes of being. ${ }^{6}$ In this way, Heidegger (1971) suggests,

In a historical change, some practices that were marginal become central, and some central practices become marginal. Reconfiguration is thus not the creation of a genius, but the drawing up of the reserve of marginal practices bestowed by the culture as from a well ( $p .76)$.

The work of the school and the teachers, from this perspective, act or work - through the medium of a new language- to open an alternate historically situated being. In other words, the teacher and the school by way of setting-into-work new truths - the ways in which beings are revealed-thrusts up the unfamiliar and extraordinary and at the same time thrusts down the ordinary. This thrusting can only occur, according to Heidegger, by way of connection to some historical experiences and ways of being already realized or experienced. For example, Heidegger (1971) presents an example of a radical cultural transformation: the transformation of the Hebrew world into the Christian world. Heidegger (1971) points out that if Jesus had not had some basis in the previous practices-something bestowed by the past-he would not have been intelligible to the Hebrews. Thus, it is essential that the grounding of a new world - introduction of Spanish in our example-takes up and makes central a marginal practice already bestowed. ${ }^{7}$

In summary, Heidegger implicitly outlines two stages to cultural transformation: 1) a reconfiguration that thrusts down the ordinary and introduces the extraordinary; and 2) an articulation that focuses, and stabilizes or grounds the new style. As presented in the above examples, becoming a municipality, looking to the American ways of being, the rebuilding of Chichen, and the establishment of a new language and educational system contributed, among other things, to the thrusting down of ordinary practices while at the same time articulating new styles, worlds, and modes of being, which together served

\footnotetext{
${ }^{6}$ This point was already eluded during the discussion of the Americans being interpreted as the "Red People" coming to bring light to the Maya civilization. In this way, the interactions with the Americans were already grounded in previous modes of being.

${ }^{7}$ On this point, it is interesting that throughout Redfield's (1950) account there seems to be a tension between cultural changes and new ways of life on the one hand and old traditions on the other. From a Heideggerian perspective, traditional values must guide the course of progress otherwise new modes of being cannot be intelligible. Therefore the tension is a natural and necessary part of cultural change.
}

as a catalyst for cultural change.

\section{Consequences of Cultural Change}

After attempting to outline a few catalysts of cultural change in Chan Kom, we now turn to examine some of the conesquences of these changes and explore how styles, worlds and being of Chan Kom residents are transformed in more detail. In this 'going-deeper' into the process of cultural change, two main examples are presented. The first includes changes in equipment use and modes of dress, followed by changes in religious practices and beliefs.

Becoming a free municipality, increasing the contact with American worlds and styles and the spread of the Spanish Language, together facilitated changes in and uses of equipment; which, in turn, reflect changes in being Maya in Chan Kom. As Heidegger points out, dasien-the particular ways in which humans take a stand on their being-is intimately connected to the worlds in which we exists and the equipment therein. Therefore, changes in the referential totality in general, or equipment use in particular, one could reasonably assume, ini- tiate changes in being. For Chan Kom residents, this is witnessed, among other things, in the introduction of more mechanized machinery, changes in agriculture, new architectural designs, and basic equipment editions such as tables and chairs that were not present in Chan Kom worlds before the 1920s. These additions to or changes in Chan Kom worlds allowed for or opened the possibility of new ways of being a villager Chan Kom.

Consequences of the shift in these referential totalities are exemplified by changes in women's dress and changes in men's footwear between the years of 1921 and 1945. Redfield (1950) notes that changes in dress were primarily from folk to city; that is, the introduction of footwear and new modes of dresssomething not common in Chan Kom and the surrounding villages at the turn of the $20^{\text {th }}$ century - created two modes of being in dialogue with each other: modern and traditional. ${ }^{8}$ Shoes and dresses, according to Redfield (1950), tend to separate the wearer from the traditional ways of life. "Shoes and dresses mean being advanced” a Chan Kom resident is quoted saying in Redfield (1950: p. 41). Indeed, Redfield notes that with the changes in women's dresses in particular their participation in the work of the milpa and in getting firewood declines. New forms of dress, therefore, alter the ways in which women can participate in the regular activities of social life thus altering the stance they take with regard to their being. Furthermore, Redfield notes that a new type of girl occurs in Chan Kom not seen in 1931 during his first visit, "a girl who joins with zest in baseball with friends and neighbors, including boys, ${ }^{9}$ "and who "speaks up when spoken to and has not the shy, almost voiceless and completely unassertive, manner that prevailed among young women in former generations” (pp. 134-135). Form this perspective, these changes reveal and articulate to others in the community styles and worlds wherein a different stance with

\footnotetext{
${ }^{8}$ In addition, as the residents of Chan Kom continually moved toward progress, Redfield (1950) notes their temporal association gradually shifted from retrospective to prospective. Being Maya in Chan Kom, therefore, was in a sense, divided in two: there becomes the what-it-is-to-be a resident of Chan Kom largely the traditional understanding as well as the what-it-isdesired-to-be or the modern understanding.

${ }^{9}$ This is a significant change as well that was introduced due to increased contact with city life. Previously male and female contact before certain ages was very conservative and the social norms prohibited significant contact between the sexes (Redfield \& Rojas, 1934).
} 


\section{A. R. HATALA}

regard to one's being can be taken that was previously marginal or unavailable. ${ }^{10,11}$

To interpret these examples and their implications, let us turn to Heidegger's (1971) analysis of the work of art where he outlines arts capacity to reveal and articulate worlds. Heidegger demonstrates this idea by analyzing a Van Gough painting of a peasant woman's shoes. Heidegger claims that the shoes in Van Gough's painting are not so much a symbol that points beyond them to something else. Instead, Heidegger argues that the painting of a peasant women's shoes reveal the shoes themselves in their truth; that is, the shoes reveal the world of the peasant women thus allowing others to witness and approach that world. From Heidegger's perspective, then, art-anything that acts to disclose a world of being - not only manifests the style of a world but also articulates it, thereby facilitating the crucial sharedness dimension of cultural systems. In other words, Heidegger (1971) claims that works of art, in their working, articulate worlds in order to produce a shared understanding of being and style. In this way, footwear in generalor the sandals in particular as a new style of footwear in Chan Kom-become works of art, in that, they reflect new truths of being Maya and serve to articulate these new styles of being to those in the surrounding environment, which thereby facilitates a new shared or common meaning of being Maya in Chan Kom. On this note, Taylor (1979) makes a similar observation in his distinction between common meanings and inter-subjective meanings. For Taylor (1979), as with Heidegger (1971), articulation is the way in which common meanings work and form the grounds of community life:

Common meanings are the basis of community. Inter-subjective meanings give a people a common language to talk about social reality and a common understanding of certain norms, but only with common meaning does this common reference world contain significant common actions, celebrations, and feelings ( $p$. 60).

From the previous example, the modern shoes and dress for the Chan Kom people, like the peasants shoes in Van Gough's painting, articulate and help construct a common meaning of what it means to be Chan Kom during their years of progress and change, thereby reflecting new worlds, styles and modes of being for others to witness, share in and experience.

During both ethnographic investigations, Redfield and Rojas (1934) and Redfield (1950) note that Religious beliefs and practices form an intimate and vital dimension to life in Chan Kom. ${ }^{12}$ During the 1920 s and 1930 s religious life is described

\footnotetext{
${ }^{10}$ The villagers refer to this as catrina; that is, one who wears city clothing. It is common, Redfiled (1950) says, that people will say that person has gone catrin if they see them wearing modern or city clothes (pp. 40-41).

${ }^{11}$ According to Heidegger (1971), changes in a referential totality of worlds and being, reflects changes in the way styles and truths of being are disclosed. It is interesting to note, then, that Redfield (1950) suggests that these changes in dress and shoes are minor and amount to nothing significant in the long run, stating, "what is behind, inside, more intimate, is much less changed, with regard to the tools and techniques as also with regard to ideas and attitudes" (p. 45). From a Heideggarian perspective, however, this is not the case due to the subject/object distinctions being discounted. Form this perspective, it is not just the "front piece of life that has changed" as Redfield (1950: p. 42) suggests in terms of the introduction of new equipment; rather, the so-called front piece of life must be taken to reflect changes in life-as-lived wherein external and internal distinction are not to be made with any significance.

${ }^{12}$ For purposes of this paper, "religion” is understood from James (1902) as, "the feelings, acts, and experiences of individual men in their solitude, so far as they apprehend themselves to stand in relation to whatever they may consider the divine” (p. 34)
}

as an amalgamation of traditional Maya and Catholic religious systems. For example, Redfield and Rojas (1934) note that the symbol of the cross was seen as much a representation of Jesus' sacrifice as it was a symbol of the four sacred directions. Within this religious landscape, there was a strong belief in the Santos (guardian spirits much like the Catholic saints) for both individuals and the entire village. Religious practices, then, generally take the form of ceremonies and rituals that were offered for the Santos and other spirits for both propriation and atonement. "A man's moods and his needs" Redfield and Rojas (1934) observe, "are objectified in a variety of spirits, and the expression of his relationships to these spirits is institutionalized in ritual” (p. 107). The novena and village fiesta, in particular, are larger gatherings of ritual worship, of which sicknesses are usually the most common initiating circumstance. In this regard, h-men or village spiritual leaders, not unlike shamans, are central in initiating and maintaining religious, and by association, therapeutic practices. ${ }^{13}$ The priestly and therapeutic functions for these individuals, therefore, are closely related. The h-men are typically more inclined toward traditional Maya practices and usually work alongside or in conjunction with a ritual chanter that is generally more embedded in Catholicism (Molesky-Poz, 2006; Redfield, 1950). In all likelihood, however, distinctions between these two religious individuals are significantly blurred. Both spiritual leaders, for example, make regular use of a ritual altar understood and described as a representation of the world itself, and both religious leaders are seen to be set apart from and "sacred" to the mundane everyday life in Chan Kom. ${ }^{14}$ Thus, significant overlap between these socalled sacred-worlds and the everyday-worlds everywhere abounds Chan Kom daily life (Redfield \& Rojas, 1934).

Changes in the religious landscape of the Chan Kom peoples are noted to occur most significantly between the years of 1930 and 1940. During this time a Protestant Evangelical movement made its way to the outskirts of the Yucatán and began preaching its message. Nearly one half of the Chan Kom residents fell under the influence of the Evangelical movement and became its avowed supporters, while the others remained within the traditional Maya and Catholic systems. Consequently, the strict teachings of the Evangelicals directed towards the cult of the Santos - a religious system previously cherished by all, now became sinful for many. Moreover, candles on the altars were becoming taboo and many traditional ceremonies lost their appeal. Naturally a schism occurred in the community bringing with it disunity, mistrust and separation. In the end however, many village leaders became aware of this disunity and began to back away from the Protestant movement in the hopes that unity could return to Chan Kom. In the wake of this religious disruption, a new mode of being with regard to religion appeared.

From a Heideggerian perspective, prior to the advent of Evangelical Protestantism, the style of one's religious life for a Chan Kom villager was unreflective and remained withdrawn and within the background of all activity. It was not a topic of

\footnotetext{
${ }^{13}$ Although it will not be discussed here in detail, Redfield and Rojas (1934) note that transformations in the role of the h-men were already occurring in Chan Kom during the 1920s. Most notably was the h-men's change in power from a person-above to a person more in line with the other members of the village. This reflects, Redfield and Rojas (1934) note, an attitudinal change due to increasing contact with larger or more modern cities.

${ }^{14}$ Here I draw on Durkhiem's (1912) understanding of religion wherein it is, "a unified system of beliefs and practices relative to sacred things, that is to say, things set apart and surrounded by prohibitions” (p. 46).
} 
deep reflection any more than the growing of crops, as it was a normal part of everyday life and an integral part to one's being. Through the introduction of a distinct way-to-be-religious, "religion”, an idea previously undeserving of deep reflection, began to occupy a central place in the mind of the Chan Kom peoples. In other words, a resident of Chan Kom, due to the introduction of Protestantism, can now take a stand on their being with regard to religion, as it, religion, has moved from the implicit pre-ontological withdrawn aspect of being, to the explicit conscious realm of concerning-life. Indeed, Redfield (1950) says, "religion" for the Chan Kom villager, is now a matter to talk about, to take into practical consequence, to think over" (p. 112). Furthermore, Redfield (1950) posits, "Where before the conduct of the religious life was as unreflective and inevitable as sunrise or spring it is now purposeful it is now a thing defended” (p. 119). From a Heideggerian perspective, therefore, we can infer that one's way of being - initially unnoticed and unreflective - can be made known to oneself only, unless, and until it is thrown into relief by another mode of being. Whenever multiplicity of worlds, style and being abound within a cultural landscape, so too, it could be argued, follows self-reflection. Therefore, the introduction and adoption of new worlds and styles act not only to articulate another shared or common meaning of being, but they also become, through self-reflection, catalysts of the change itself. Geertz (1973) sums up this point nicely:

A people's ethos is the tone, character, and quality of their life, its moral and aesthetic style... Quartets, still lives, and cockfights are not merely reflections of a pre-existing sensibility analogically represented; they are positive agents in the creation and maintenance of such a sensibility (p. 451).

Within the example of a changing religious landscape, then, Evangelical Protestantism, with its practices, rites, beliefs, and experiences, and to the extent that individuals took-up these new modes, represented new worlds and styles of religious being to other Chan Kom villagers. In so doing, the style of being a Maya-catholic was thrown into relief thereby creating a new problem with regard to one's stand in the world. Individual change, then, in this case, is the result of witnessing the way in which one currently takes a stand on their being through contrast to an atypical stance. Cultural changes, it may be argued, would then be emergent properties or holistic totals of these individual processes.

\section{Conclusion}

This paper attempted to depict some aspects of cultural transformation in the Maya village of Chan Kom based on the ethnographic accounts provided by Redfield and Rojas (1934) and Redfield (1950). Insights from Heidegger's (1962) "Being and Time" and his (1971) "The origin of the Work of Art", wherein the ontological structures and intimate relations between worlds, being, and style are presented, formed the analytic lens through which cultural changes were interpreted. From this analysis, three so-called catalysts for cultural change in Chan Kom were outlined: 1) the desire to be a pueblo and a "free municipality"; 2) contact with Americans and Chichen Itza; and 3) the introduction of the Spanish language within the Chan Kom school in general or through the local teacher in particular. Following this, two consequences of cultural change were presented: 1) new equipment and modes of dress; and 2) new understandings towards and practices of religion.
In the final analysis, cultural change remained a difficult and extremely complex social process to describe. Using a Hedeggerian approach however, some potentially fruitful insights emerged that might help researchers better grasp and understand the rich process of and complexities within cultural transformation. These include:

1) The normal state of rest for one's cultural style, worlds and being is generally unreflective, withdrawn and within the background of daily activity.

2) The introduction of or contact with new worlds, styles and being is often the beginning of cultural transformation by throwing into relief one's own style of being, thereby increasing self-reflection and creating a new problematic with regard to one's stand toward the world.

3) The introduction of new worlds and styles reconfigures and fosters a setting-into-work of new truths-the ways in which beings are revealed-by articulating them to the community and thereby opening new ways in which individuals can take a stand on their being, ways that were previously marginal or unavailable.

4) The grounding of a new world or setting-into-work of truth, must take up and make central a marginal practice already bestowed, otherwise the new practice will not be intelligible.

5) Language bestows the material for a new cultural style and is central to being, in that, language brings beings as beings into the open for the first time and further makes possible the founding of truth or the ways in which beings are disclosed as such.

6) The concept of the work of art-understood as anything that acts to disclose a world of being-is central to the process of cultural transformation, in that, art, or the enactment of new worlds, not only reveals the style of a world, but also articulates and illuminates it; thereby facilitating the "sharedness" or common meaning dimension of cultural systems.

7) Cultural changes are the emergent properties or holistic totals of individual changes as a result of contact with other styles, worlds and ways of being. Individual transformation, then, is at the center of cultural change.

Redfield suggests that the future of Chan Kom and its residence is uncertain. Many changes he interpreted as beneficial, such as increased education and opportunities for new ways of sustenance. Yet at the same time, Redfield (1950) observes the loosening of the so-called moral fabric that was knit together through many years of traditional stories, ceremonies and rituals. Skepticism of traditional Maya ways is steadily gaining influence in Chan Kom as "progress" creeps forward. To meet the future demands of life, Redfield (1950) suggests, Chan Kom needs less faith in traditional ways and more knowledge of science and modern ways-" less faith and more science is the answer" Redfield argues (p. 178). Based on the analysis here, it is instead argued that to meet the future demands of Chan Kom life and all its complexities, an integration between traditional values and modern science, rather than a replacement of one over the other, would bare the most fruit in the years to come. This argument also extends to many other Indigenous cultural groups who face similar processes of change in the face of modernity (Hatala, 2008; Hatala \& Desjardins, 2010). As outlined, change is a slow blending of worlds, and not a linear progression or smooth binary transition. Cultural transformation is a messy collision of worlds, styles and being, which work together to create a host of new stances one can 


\section{A. R. HATALA}

take toward the world. Plurality, it would seem, is unavoidable and essential in the modern age, thus including so-called faith and science, tradition and modernism.

\section{REFERENCES}

Coe, M. D. (1999). The Maya. New York, NY: Thames and Hudson Ltd.

Durkheim, E. (1912). The elementary forms of religious life. Oxford: Oxford University Press.

Geertz, C. (1973). The interpretations of Cultures. New York, NY: Basic Books.

Good, B. (1994). Medicine, rationality, and experience: An anthropological perspective. Cambridge: Cambridge University Press.

Hatala, A. R. (2008). Spirituality and aboriginal mental health. Advances in Mind Body Medicine, 23, 6-12.

Hatala, R. A. (2010). Frankl \& Freud: Friend or foe? Towards cultural \& developmental perspectives of theoretical ideologies. Psychology \& Society, 3, 1-25

Hatala, R. A., \& Desjardins, M. (2010). The spirit messenger and the traditional exemplar: Two figures of the elder among plains cree communities. Canadian Journal of Native Studies, 30, 49-81.

Heidegger, M. (1962). Being and time. In J. Macquarrie, \& E. Robinson, (Trans.), New York, NY: Harper \& Row.

Heidegger, M. (1971). The origin of the work of art. In A. Hofstadter (Trans.), Poetry, language, thought, New York, NY: Harper \& Row.

James, W. (1961). The varieties of religious experience: A study in human nature. Cambridge: Harvard University Press.
Kahn, H. E. (2006). Seeing and being seen: The Q'eqchi Maya of Livingston, Guatemala and beyond. Austin: University of Texas Press.

Keesing, R. (1990). Theories of culture revisited. Canberra Anthropology, 13, 46-60. doi:10.1080/03149099009508482

Little, W. (2004). Mayas in the marketplace: Tourism, globalization, and cultural identity. Austin: University of Texas Press.

Maurer, K. (1997). Ancient images, modern visions: Representations of Maya identity in Belize. PhD dissertation, Los Angeles: University of California.

Molesky-Poz, J. (2006). Contemporary Maya spirituality: The ancient ways are not lost. Austin: University of Texas Press.

Redfield, R. (1950). A village that chose progress. Chicago, IL: University of Chicago Press.

Redfield, R., \& Rojas, A., V. (1934). Chan Kom: A Maya village. Washington, DC: Carnegie Institution of Washington.

Taylor, C. (1979). Interpretation and the sciences of man. In P. Rainbow, \& W. Sullivan (Eds.), Interpretive social science, Berkley: University of California Press.

Waldram, J., Cal, V., \& Maquin, P. (2009). The Q'eqchi Healer's Association of Belize: An endogenous movement in heritage preservation and management. Heritage Management, 2, 35-54.

Watanabe, J. (1992). Maya saints and souls in a changing world. Austin: University of Texas Press.

Watanabe, J., \& Fischer, E. (2004). Pluralizing ethnography: Comparison and representation in Maya cultures, histories, and identities. Santa Fe: School of American Research Press.

Thompson, E. J. (1970). Maya history and religion. Norman: University of Oklahoma Press. 